\title{
Rotation of an oblate satellite: Chaos control (Corrigendum)
}

\author{
M. Tarnopolski (i)

\begin{abstract}
Astronomical Observatory, Jagiellonian University, Orla 171, 30-244 Kraków, Poland e-mail: mariusz. tarnopolski@uj .edu.pl
\end{abstract} \\ A\&A, 606, A43 (2017), https://doi . org/10 . 1051/0004-6361/201731167 \\ Key words. celestial mechanics - chaos - methods: numerical - errata, addenda \\ Equation (25) in the original paper should read

\section{References} \\ Ciraolo, G., Chandre, C., Lima, R., Vittot, M., \& Pettini, M. 2004, Celest. Mech. \\ Dyn. Astr., 90, 3
}

$\mathcal{F}_{s}=-\frac{1}{s}\left\{\Gamma \mathcal{V}, \mathcal{F}_{s-1}\right\}$

in agreement with Eq. (8) in Ciraolo (2004). Fortunately, this was only a typing error, and as such it does not affect any results published in the paper. 